\title{
Correction to: Equality in the Home and in the Community: a Multilevel Longitudinal Analysis of Intimate Partner Violence on the Ecuadorian-Colombian Border
}

\author{
Sarah Treves-Kagan ${ }^{1} \cdot$ Amber Peterman $^{2} \cdot$ Nisha C. Gottfredson $^{1} \cdot$ Andrés Villaveces $^{3} \cdot$ Kathryn E. Moracco $^{1}$. \\ Suzanne Maman ${ }^{1}$
}

Published online: 15 December 2020

(C) Springer Science+Business Media, LLC, part of Springer Nature 2020

\section{Correction to: J Fam Viol (2020) https://doi.org/10.1007/s10896-020-00234-5}

The original version of this article unfortunately contained a mistake. Three references masked for peer review were not updated. Authors 2015, 2017a, 2017b refer to Peterman, Schwab, Roy, Hidrobo, \& Gilligan 2015; Behrman, Peterman, \& Palermo 2017; and Peterman, Pereira, Bleck, Palermo, \& Yount 2017, respectively.

Full references are:

Peterman, A., Schwab, B., Roy, S., Hidrobo, M., \& Gilligan, D. (2015). Measuring women's decisionmaking: Indicator choice and survey design experiments from cash and food transfer evaluations in Ecuador, Uganda and Yemen.
Washington, D.C.: International Food Policy Research Institute.

Behrman, J. A., Peterman, A., \& Palermo, T. (2017). Does keeping adolescent girls in school protect against sexual violence? Quasi-experimental evidence from East and Southern Africa. Journal of Adolescent Health, 60(2), 184-190.

Peterman, A., Pereira, A., Bleck, J., Palermo, T. M., \& Yount, K. M. (2017). Women's Individual Asset Ownership and Experience of Intimate Partner Violence: Evidence From 28 International Surveys. American Journal of Public Health, 107(5), 747-755. doi:10.2105/ajph.2017.303694

The original article has been corrected.

The online version of the original article can be found at https://doi.org/ 10.1007/s10896-020-00218-5

Sarah Treves-Kagan

kagan.sarah@gmail.com

Amber Peterman

amberpeterman@gmail.com

Nisha C. Gottfredson gottfredson@unc.edu

Andrés Villaveces avillav@email.unc.edu

Kathryn E. Moracco moracco@email.unc.edu
Suzanne Maman

maman@email.unc.edu

Department of Health Behavior, Gillings School of Global Public Health, University of North Carolina at Chapel Hill, 135 Dauer Dr., Chapel Hill, USA

2 Department of Public Policy, University of North Carolina at Chapel Hill, 131 S Columbia St, Chapel Hill, NC, USA

3 Department of Epidemiology, Gillings School of Global Public Health, University of North Carolina at Chapel Hill, 135 Dauer Dr., Chapel Hill, USA 